\title{
Effects of inflation and time value of money on an inventory system with deteriorating items and partially backlogged shortages
}

\author{
Chandra K. Jaggi ${ }^{\mathrm{a}^{*}}$, Aditi Khanna ${ }^{\mathrm{a}}$ and Nidhi ${ }^{\mathrm{b}}$
}

\begin{tabular}{l}
${ }^{a}$ Department of Operational Research, \\
${ }^{b}$ Centre for Mathematical Sciences, Ba \\
\hline C H R O N I C L E \\
\hline Article history: \\
Received July 222015 \\
Received in Revised Format \\
Septmber17 2015 \\
Accepted October 142015 \\
Available online \\
October 15 2015 \\
\hline Keywords: \\
Inventory \\
Deterioration \\
Partial Backlogging \\
Inflation \\
Time value of money \\
Finite planning horizon
\end{tabular}

\section{Introduction}

Traditionally items kept as inventory are tacitly assumed to have an infinite lifespan or presumed to be perfect throughout the business cycle. But in reality, many products impair in quality, character or value due to spoilage, vaporization, dryness or due to changing technological trends. Hence the item may not serve the purpose after a period of time and will have to be discarded as it cannot be used to satisfy the future demand of customers. Thus for managing inventory in a realistic scenario, the effect of 
deterioration cannot be ignored. In the past many researchers have analyzed different inventory problems incorporating the phenomenon of deterioration; the research has been summarized in different survey papers (Raafat et al. (1991), Goyal \& Giri (2001) and Bakker et al. (2012)).

Moreover in today's unpredictable market and due to changing consumers' preferences, a stock-out situation may arise in any business. Stock-outs are frustrating for the consumer and costly for the retailer, as they are likely to lose almost one-half of the intended purchases when a consumer confronts an outof-stock item. According to the literature of inventory control theory, most of the inventory models were developed under the assumption that "shortages are allowed and completely backlogged”. However nowadays customers are often fickle and increasingly less loyal, which eventually results in only a fraction of the customers waiting for the product till they arrive. In reality, for fashionable commodities and high-tech products with short life cycles, the backorder rate decreases with the length of waiting time. Hence in today's market structure, partial backlogged shortages are a more practical assumption for better business performance.

The first effort in which customer's impatience functions is proposed seems to be that by (Abad, 1996). Abad derived a pricing and ordering policy for a variable rate of deterioration and partially backlogging. The partially backlogging was assumed to be exponential function of waiting time till the next replenishment. Chang \& Dye (1999) developed an inventory model in which the proportion of customers who would like to accept backlogging is the reciprocal of a linear function of the waiting time. Teng et al. (2002) and Teng et al. (2003) then extended the fraction of unsatisfied demand backordered to any decreasing function of the waiting time up to the next replenishment. Teng \& Yang $(2004,2007)$ further generalized the partial backlogging EOQ model to allow for time-varying purchase cost. Dye et al. (2007) modified the Abad's model taking into consideration the backorder cost and lost sale. Shah \& Shukla (2009) also developed a deterministic inventory model in which items are subject to constant deterioration and shortages are partially backlogged.

Apart from the above mentioned facts, inflation is a crucial attribute of today's esoteric economy which cannot be shrugged off. The term 'inflation' particularly used in an economic context literally means to blow up or get bigger. However the most common economic meaning of inflation is: reduction in the value of money i.e., monetary depreciation. As a result prices of commodities rise which subsequently curbs the purchasing power. Further from the financial perspective, inventories correspond to substantial investment in capital for any organization; hence it would not be ethical if the effects of inflation and time value of money are not considered while determining the optimal inventory policy.

In the past many authors have developed different inventory models under inflationary conditions with different assumptions. To relax the assumption of non inflationary effects on costs, (Buzacott, 1975) and (Misra, 1975) simultaneously developed an EOQ model with a constant inflation rate for all associated costs. Bierman \& Thomas (1977) proposed the economic order quantity model considering the effect of both inflation and time value of money with incorporated the discount rate. Misra (1979) gave a note on the optimal inventory management under the impact of inflation. Datta \& Pal (1991) studied the effect of inflation and time-value of money on an inventory model with linear time-dependent demand rate and shortages. Several other researchers have worked in this area like (Wee \& Law, 1999, 2001), (Yang et al., 2001), (Jaggi \& Goel, 2005) and many more. (Moon et al., 2005) developed EOQ model for deteriorating items under inflation and time discounting. (Jaggi et al., 2006) investigated the optimal ordering policies for deteriorating items with inflation-induced demand. Chern et al. (2008) proposed partial backlogging inventory lot-size models for deteriorating items with fluctuating demand under inflation. Jaggi \& Khanna (2008) studied the impact of inflation and credit policies on a production lot size model. Thangam \& Uthayakumar (2010) developed an inventory model for deteriorating items under inflationary conditions using a discounted cash flow (DCF) approach over a finite planning horizon in which the demand rate was a function of inflation. Yang et al. (2010) presented an inventory model for deteriorating items with stock dependent consumption rate and partially backlogged shortages under 
inflation. They have considered time varying replenishment cycles and shortage intervals, but they did not incorporate the effect of inflation on the cost parameters. Bansal (2013) developed the inventory model for deteriorating items under inflation with two cases: first is shortages are not allowed and second is shortages are allowed with complete backlogging. Recently, (Bhaula \& Kumar, 2014) derived an optimal inventory replenishment policy for two parameters Weibull deterioration with stock-dependent consumption rate, shortages under inflation and time discounting over a finite planning horizon.

However, all the above mentioned papers on inflation and shortages, have considered the impact of inflation in their modelling, and the prices they charge to their customers during the stock out period are the prices of the next period, i.e., the time at which the retailer receives his ordered lot, which is rather immoral. Indeed by charging them the inflated price of the next period, retailers are penalizing their loyal customers. Moreover, it is observed that the customers who experience stock-out would be less likely to buy again from the retailer, as they may have alternative stores in the market to purchase the same product. Thus in order to convert the lost sales into sales, the retailer offers them an incentive, by charging them the price prevailing at the time of placing an order, instead of the current inflated price. This encourages the customer to wait for his order and come back, and subsequently the retailer is able to reduce his lost sales. Such a concept has not been addressed by the researchers yet in their modeling. Furthermore, the study has been conducted using Discounted Cash Flow (DCF) approach, as it helps to determine organization's current value according to its estimated future cash flows in inventory analysis. Finally the model has been validated with the help of a numerical example. A comprehensive sensitivity analysis has also been performed to investigate the effects of deterioration, inflation and backlogging parameter on the optimal inventory replenishment policies.

\section{Assumptions and Notations}

The following assumptions and notations have been used in the entire paper.

\subsection{Assumptions}

1. Demand is deterministic and occurs uniformly over the period.

2. Replenishment is instantaneous, but its size is finite.

3. The time horizon of the inventory system is finite.

4. Lead time is constant.

5. Shortages are partially backlogged and are fulfilled at the beginning of the next cycle. The fraction of the shortages backordered is assumed to be a differentiable and decreasing function of time $t$, denoted by $\delta(t)$. Thus the partial backlogging rate is defined to be $\delta(t)=\mathrm{e}^{-\delta(T-t)}$, where $\delta(>0)$ is the backlogging parameter and $(T-t)$ is waiting time up to the next replenishment.

6. A constant fraction $\theta(0 \leq \theta \leq 1)$ of the on-hand inventory deteriorates per unit time.

7. There is no repair or replenishment of the deteriorated items during the inventory cycle.

8. A Discount Cash Flow (DCF) approach is used to consider the various costs at various times.

\subsection{Notations}

$H$

$n$

$T$

$A_{0}$

$h_{0}$

$C_{0}$

So

Lo the length of the whole planning horizon

the number of replenishment over $[0, H]$

the replenishment cycle and $H=n T$

the ordering cost per order at time zero

the holding cost per unit per unit time at time zero

the purchase cost per unit at time zero

the shortage cost per unit per unit time at time zero

The lost sale cost per unit per unit time at time zero 


\begin{tabular}{|c|c|}
\hline $\begin{array}{l}p_{0}\left(p_{0}>C_{0}\right) \\
\theta\end{array}$ & $\begin{array}{l}\text { selling price per unit of item at time zero } \\
\text { the deterioration rate }\end{array}$ \\
\hline$I_{i}(t)$ & the inventory level at time $t$, in $\mathrm{i}^{\text {th }}$ interval, where $t \in[0, H]$ \\
\hline$t_{i}$ & the time at which the inventory level reaches zero in $\mathrm{i}^{\text {th }}$ replenishment \\
\hline$q_{i}$ & 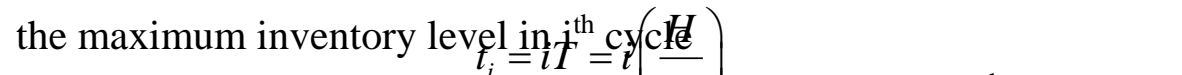 \\
\hline$I B_{i}$ & the maximum backorder units during stbck-out period in $\mathrm{i}^{\text {th }}$ cycle \\
\hline$Q_{i}$ & the economic order quantity in $\mathrm{i}^{\text {th }}$ cycle \\
\hline$r$ & the discount rate, representing the time value of money \\
\hline$\alpha$ & the inflation rate \\
\hline$T P(k, n)$ & the present worth of total profit \\
\hline
\end{tabular}

\section{Mathematical Formulation}

The planning horizon $H$ has been divided into $n$ replenishment equal cycles of length $T$, such that $t_{0}=0, t_{n}=H, t_{i}-t_{i-1}=T$ and $t_{i}=i T(i=1,2, \ldots, n)$.

Consider the $\mathrm{i}^{\text {th }}$ cycle $\left(t_{i-1} \leq t \leq t_{i}\right)$, which begins with shortages, as the retailer does not have any stock on hand at that time, and the order lot is scheduled to arrive at $t_{i 1}$. Hence during the time period $\left(t_{i-1}, t_{i 1}\right)$ shortages are allowed to accumulate. However, only a fraction of the customers wait for the product till they arrive, so shortages are partially backordered, and partially lost. Thus a portion of the order quantity received at $t_{i 1}$ is used to satisfy the backorders, and the remaining is used to satisfy the demand of the current cycle. So during the time period $\left(t_{i 1} t_{i}\right)$, the inventory gradually diminishes to zero due to the combined effect of demand and deterioration.

Now, $t_{i-1}=t_{i 1}-k T \Rightarrow t_{i 1}=\{(i-1)+k\} \frac{H}{n},(i=1,2, \ldots, n),(0 \leq k \leq 1)$,

where $k T$ is the fraction of the cycle having shortages.

The inventory scenario is depicted graphically in Fig.1.

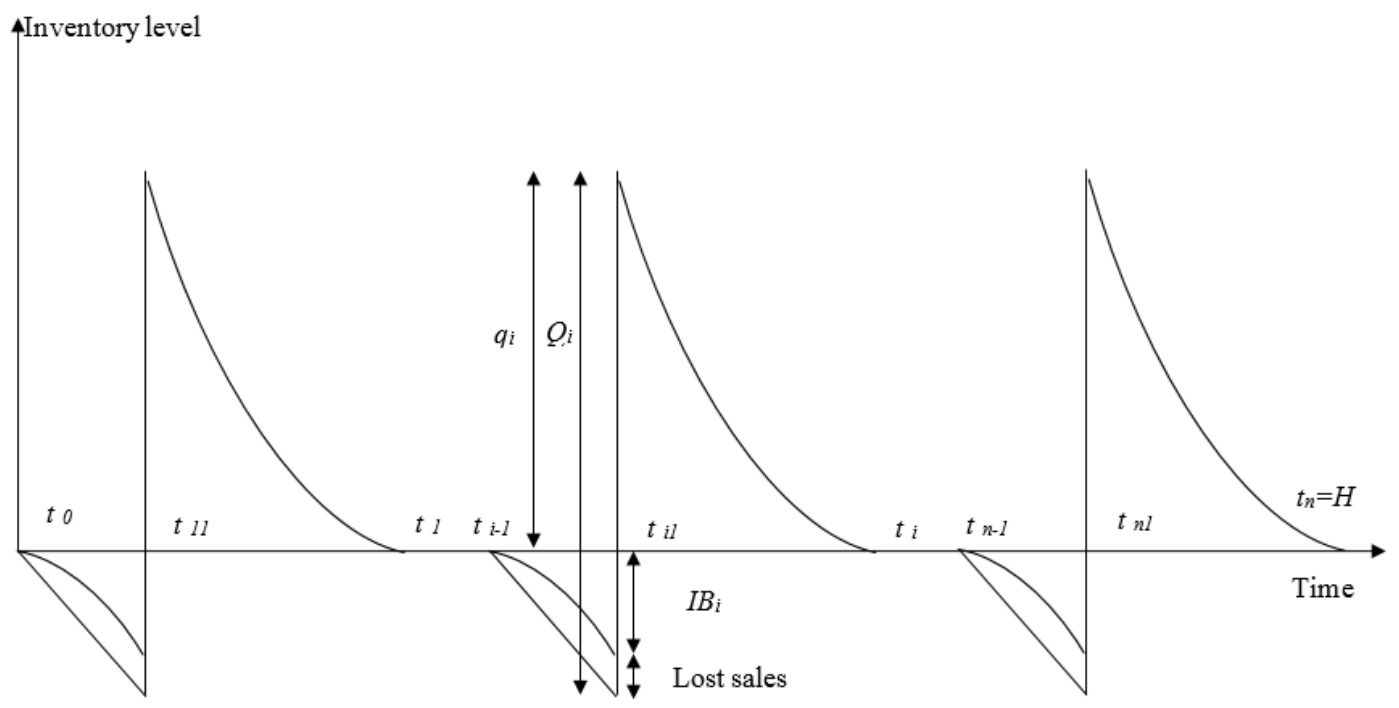

Fig. 1. Pictorial Representation of Inventory system 
The inventory level at any time $t$ during the $i^{\text {th }}$ replenishment cycle is governed by the following differential equations:

During the time interval $\left[t_{i 1}, t_{i}\right]$ the inventory is depleted by the combined effect of demand and deterioration. Hence, the inventory level at any time $t$ is

$$
\frac{d I_{i}(t)}{d t}+\theta I_{i}(t)=-D \quad, t_{i 1} \leq t \leq t_{i} \quad i=1,2, \ldots, n
$$

The solution of the differential equation given in Eq. (1) with the boundary condition $I\left(t_{i}\right)=0$ is

$$
I_{i}(t)=\frac{D}{\theta}\left\{e^{\theta\left(t_{i}-t\right)}-1\right\}
$$

Further, the time interval $\left[t_{i-1}, t_{i 1}\right]$ is the stock out period, with partially backlogged shortages. In this case only a fraction i.e. $e^{-\delta(T-t)}$ of the total shortages is backlogged while the rest is lost, where $t \in\left[t_{i-1}, t_{i 1}\right]$. Hence, the inventory level at any time $t$ during the time interval $\left[t_{i-1}, t_{i 1}\right]$ in the $\mathrm{i}^{\text {th }}$ replenishment cycle is governed by the following differential equation:

$$
\frac{d I_{i}(t)}{d t}=-D e^{-\delta\left(t_{i 1}-t\right)}, \quad t_{i-1} \leq t \leq t_{i 1} \quad i=1,2, \ldots, n
$$

After using the boundary condition $I\left(t_{i-1}\right)=0$, the solution of the differential equation (3) is

$$
I_{i}(t)=\frac{D}{\delta}\left\{e^{-\delta\left(t_{i 1}-t_{i-1}\right)}-e^{-\delta\left(t_{i 1}-t\right)}\right\} i=1,2, \ldots, n
$$

The maximum amount of positive inventory is

$$
q_{i}=I\left(t_{i 1}\right)=\frac{D}{\theta}\left\{e^{\theta\left(t_{i}-t_{i 1}\right)}-1\right\} \text { (using Eq. (2)) }
$$

The maximum number of backordered units is

$$
I B_{i}=-I\left(t_{i 1}\right)=\frac{D}{\delta}\left\{1-e^{-\delta\left(t_{i 1}-t_{i-1}\right)}\right\} \text { (using Eq. (4)) }
$$

Hence, the economic order quantity $Q_{i}$ for $\mathrm{i}^{\text {th }}$ cycle is

$$
Q_{i}=q_{i}+I B_{i}=\frac{D}{\theta}\left\{e^{\theta\left(t_{i}-t_{i 1}\right)}-1\right\}+\frac{D}{\delta}\left\{1-e^{-\delta\left(t_{i 1}-t_{i-1}\right)}\right\}
$$

Moreover, the present model has been developed under inflationary conditions. Hence, one simple way of modeling is to assume $\alpha$, the constant rate of inflation. Therefore, the various costs as the ordering cost, unit cost of the item, inventory carrying cost, shortage cost, cost due to lost sales and selling price at any time $t$ are given by

$$
A(t)=A_{0} e^{\alpha t}, C(t)=C_{0} e^{\alpha t}, h(t)=h_{0} e^{\alpha t}, S(t)=S_{0} e^{\alpha t}, L(t)=L_{0} e^{\alpha t}, p(t)=p_{0} e^{\alpha t}
$$

The model begins at time $t_{0}$, when shortages start to accumulate at the price of $p\left(t_{0}\right)=p_{0}$ till $t_{11}$. At $t_{11}$, an ordered lot is received in the system from which the backorders accumulated till $t_{11}$ are satisfied at the same prevalent price $p\left(t_{0}\right)$, when the customers have placed their order. However, due to inflation the 
selling price of the items would be $p\left(t_{1}\right)=p_{0} e^{\alpha t_{1}}$ for the customers coming during the period $\left(t_{11}, t_{1}\right)$. The same process would be followed for the $i^{\text {th }}$ cycle.

Now, the present value of the profit for the $\mathrm{i}^{\text {th }}$ replenishment cycle is given by sales revenue - ordering cost - purchasing cost - holding cost -shortage cost - cost due to lost sales. Thus, by assuming continuous compounding of inflation and time value of money, the present value of the various costs for $\mathrm{i}^{\text {th }}$ cycle are evaluated as follows:

1. Present worth of the revenue for $\mathrm{i}^{\text {th }}$ cycle is

(i) Present worth of the revenue from the sales is $p\left(t_{i 1}\right) e^{-r t_{i 1}} \int_{t_{i 1}}^{t_{i}} D e^{-r t} d t$

(ii) Now to calculate the present worth of the revenue from the shortages, the selling price of the items should be $p\left(t_{(i-1) 1}\right)$, i.e., the price prevalent when the shortages start to occur.

Present worth of the revenue from the shortages is $p\left(t_{(i-1) 1}\right) e^{-r t_{i 1}} \int_{t_{i-1}}^{t_{i 1}} D e^{-\delta\left(t_{i 1}-t\right)} d t$

Hence, the total present worth of the revenue is

$$
\begin{aligned}
& S R_{i}=p\left(t_{i 1}\right) e^{-r t_{i 1}} \int_{t_{i 1}}^{t_{i}} D e^{-r t} d t+p\left(t_{(i-1) 1}\right) e^{-r t_{i 1}} \int_{t_{i-1}}^{t_{i 1}} D e^{-\delta\left(t_{i 1}-t\right)} d t \\
& =p_{0} D\left[e^{(\alpha-r) t_{i 1}}\left\{\frac{\left(e^{-r t_{i 1}}-e^{-r t_{i}}\right)}{r}\right\}+e^{\alpha t_{(i-1) !}} e^{-r t_{i 1}}\left\{\frac{\left(1-e^{-\delta\left(t_{i 1}-t_{i-1}\right)}\right)}{\delta}\right\}, i=1,2, \ldots, n .\right.
\end{aligned}
$$

2. Present worth of the ordering cost for $\mathrm{i}^{\text {th }}$ cycle is

$$
A_{i}=A\left(t_{i 1}\right) e^{-r t_{i 1}}=A_{0} e^{(\alpha-r) t_{i 1}}, i=1,2, \ldots, n .
$$

3. Present worth of the purchase cost for $\mathrm{i}^{\text {th }}$ cycle is

$$
\begin{aligned}
P C_{i} & =Q_{i} C\left(t_{i 1}\right) e^{-r t_{i 1}}=Q_{i} C_{0} e^{(\alpha-r) t_{i 1}} \\
P C_{i} & =C_{0} e^{(\alpha-r) t_{i 1}}\left[\frac{D}{\theta}\left\{e^{\theta\left(t_{i}-t_{i 1}\right)}-1\right\}+\frac{D}{\delta}\left\{1-e^{-\delta\left(t_{i 1}-t_{i-1}\right)}\right\}\right], i=1,2, \ldots, n .
\end{aligned}
$$

4. Present worth of the inventory holding cost for $\mathrm{i}^{\text {th }}$ cycle is

$$
\begin{aligned}
& H C_{i}=h\left(t_{i 1}\right) e^{-r t_{i 1}} \int_{t_{i 1}}^{t_{i}} I_{i}(t) e^{-r t} d t=h_{0} e^{(\alpha-r) t_{i 1}} \int_{t_{i 1}}^{t_{i}} \frac{D}{\theta}\left\{e^{\theta\left(t_{i}-t\right)}-1\right\} e^{-r t} d t \\
& =\frac{h_{0} D}{\theta} e^{(\alpha-r) t_{i 1}}\left[\frac{\left(e^{-r t_{i}}-e^{-r t_{i 1}}\right)}{r}+\frac{\left(e^{\theta\left(t_{i}-t_{i 1}\right)} e^{-r t_{i 1}}-e^{-r t_{i}}\right)}{(\theta+r)}\right], i=1,2, \ldots, n .
\end{aligned}
$$


Present worth of the shortage cost for $\mathrm{i}^{\text {th }}$ cycle is

$$
\begin{aligned}
& S C_{i}=S\left(t_{i 1}\right) e^{-r t_{i 1}} \int_{t_{i-1}}^{t_{i 1}}-I_{i}(t) e^{-r t} d t=S_{0} e^{(\alpha-r) t_{i 1}} \int_{t_{i-1}}^{t_{i 1}} \frac{D}{\delta}\left\{e^{-\delta\left(t_{i 1}-t_{i-1}\right)}-e^{-\delta\left(t_{i 1}-t\right)}\right\} e^{-r t} d t \\
& =\frac{S_{0} D}{\delta} e^{(\alpha-r) t_{i 1}}\left[\frac{\left(e^{-r t_{i 1}}-e^{-\delta\left(t_{i 1}-t_{i-1}\right)} e^{-r t_{i-1}}\right)}{(\delta-r)}+\frac{e^{-\delta\left(t_{i 1}-t_{i-1}\right)}\left(e^{-r t_{i 1}}-e^{-r t_{i-1}}\right)}{r}\right], i=1,2, \ldots, n .
\end{aligned}
$$

5. Present worth of the cost due to lost sales for $\mathrm{i}^{\text {th }}$ cycle is

$$
\begin{aligned}
& L C_{i}=L\left(t_{i 1}\right) e^{-r t_{i 1}} \int_{t_{i-1}}^{t_{i 1}} D\left\{1-e^{-\delta\left(t_{i 1}-t\right)}\right\} d t \\
& =D L_{0} e^{(\alpha-r) t_{i 1}}\left[\left(t_{i 1}-t_{i-1}\right)+\frac{\left(e^{-\delta\left(t_{i 1}-t_{i-1}\right)}-1\right)}{\delta}\right], i=1,2, \ldots, n .
\end{aligned}
$$

Now, the present value of the total profit $T P_{i}$ for the $\mathrm{i}^{\text {th }}$ cycle is given by the following expression:

$$
T P_{i}=S R_{i}-\left(O C_{i}+P C_{i}+H C_{i}+L C_{i}+S C_{i}\right), i=1,2, \ldots, n .
$$

The present worth of the total profit of the system during the entire time horizon $H$ is

$$
T P(k, n)=\sum_{i=1}^{n} T P_{i}=\sum_{i=1}^{n}\left\{S R_{i}-\left(O C_{i}+P C_{i}+H C_{i}+L C_{i}+S C_{i}\right)\right\}
$$

Substituting the values of $S R_{i}, O C_{i}, P C_{i}, H C_{i}, S C_{i}$ and $L C_{i}$ from Eqs. (8-12) and Eq. (13), respectively, in Eq. (15) and after simplification, we get

$$
\begin{aligned}
& \operatorname{TP}(k, n)=p_{0} D e^{(\alpha-r) k H / n}\left\{\left(\frac{1-e^{(\alpha-2 r) H}}{1-e^{(\alpha-2 r) H / n}}\right)\left(\frac{e^{-r k H / n}-e^{-r H / n}}{r}\right)+\left(\frac{1-e^{(\alpha-r) H(n-1) / n}}{1-e^{(\alpha-r) H / n}}\right)\left(\frac{e^{-r H / n}\left(1-e^{-\delta k H / n}\right)}{\delta}\right)\right\}+p_{0} D \\
& \left(\frac{e^{-r H / n}\left(1-e^{-\delta k H / n}\right)}{\delta}\right)-e^{(\alpha-r) k H / n}\left\{A_{0}\left(\frac{1-e^{(\alpha-r) H}}{1-e^{(\alpha-r) H / n}}\right)+C_{0} D\left(\frac{1-e^{(\alpha-r) H}}{1-e^{(\alpha-r) H / n}}\right)\left(\frac{e^{\theta(1-k) H / n}-1}{\theta}+\frac{1-e^{-\delta k H / n}}{\delta}\right)\right. \\
& +h_{0} D\left(\frac{1-e^{(\alpha-2 r) H}}{1-e^{(\alpha-2 r) H / n}}\right)\left(\frac{e^{-r H / n}-e^{-r k H / n}}{r \theta}+\frac{e^{-r k H / n} e^{\theta(1-k) H / n}-e^{-r H / n}}{\theta(\theta+r)}\right)+S_{0} D\left(\frac{1-e^{(\alpha-2 r) H}}{1-e^{(\alpha-2 r) H / n}}\right) \\
& \left.\left(\frac{e^{-r k H / n}-e^{-\delta k H / n}}{\delta(\delta-r)}+\frac{e^{-\delta k H / n}\left(e^{-r k H / n}-1\right)}{\delta r}\right)+L_{0} D\left(\frac{1-e^{(\alpha-r) H}}{1-e^{(\alpha-r) H / n}}\right)\left(\frac{k H}{n}+\frac{e^{-\delta k H / n}-1}{\delta}\right)\right\}
\end{aligned}
$$

Now, the problem is to determine the optimal values of $k$ and $n$ which maximize $\operatorname{TP}(k, n)$. Since, the profit function $\operatorname{TP}(k, n)$, is a function of two variables $k$ and $n$, where $k$ is a continuous and $n$ is a discrete variable, therefore, for any given value of $n=n_{0}$ (say), the necessary condition for $T P(k, n)$ to be maximum is 
$\frac{\partial T P\left(k, n_{0}\right)}{\partial k}=0$, which gives

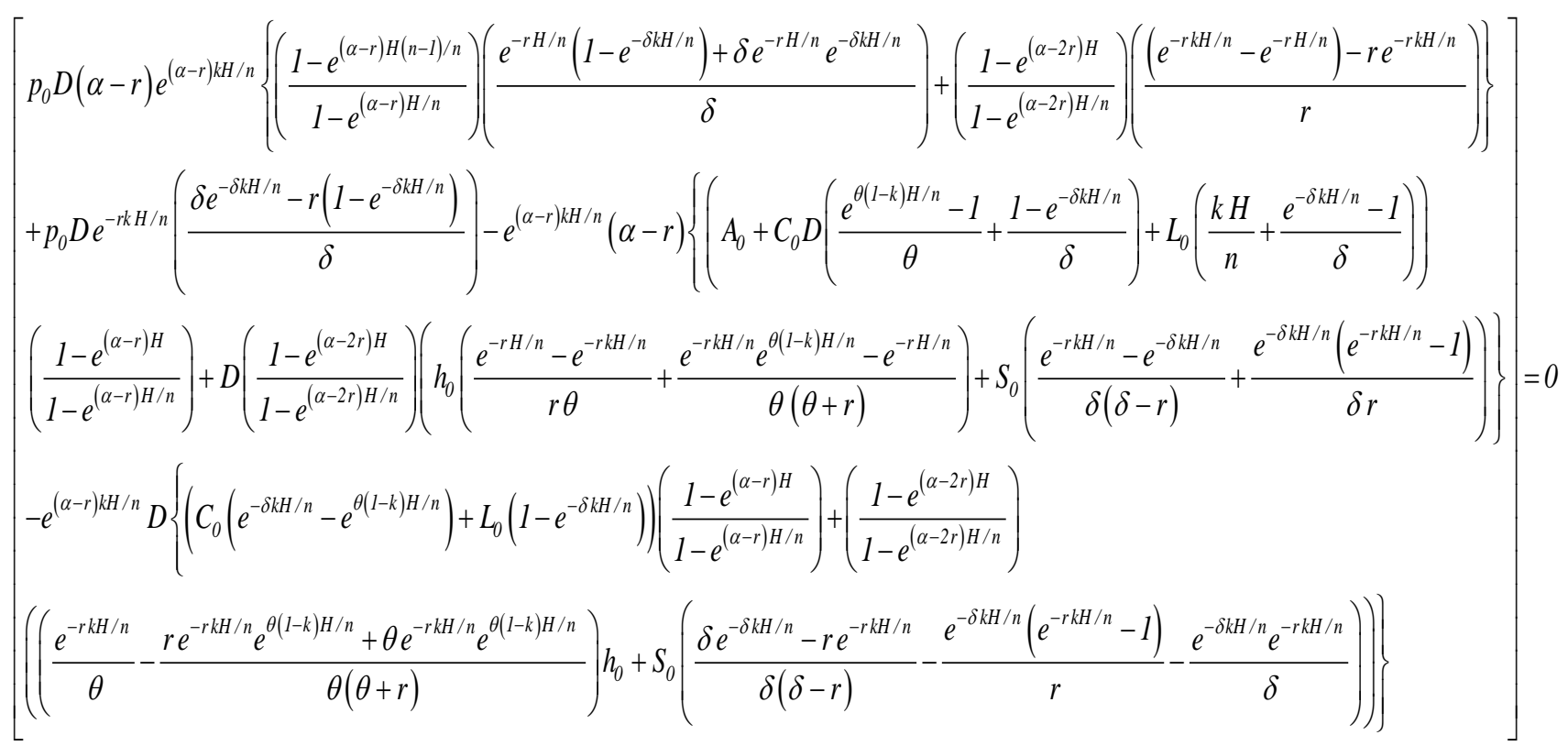

Further, for the present worth of total profit $\operatorname{TP}(k, n)$ to be concave, the following sufficient condition must be satisfied $\frac{\partial^{2} T P}{\partial k^{2}} \leq 0$. Now,

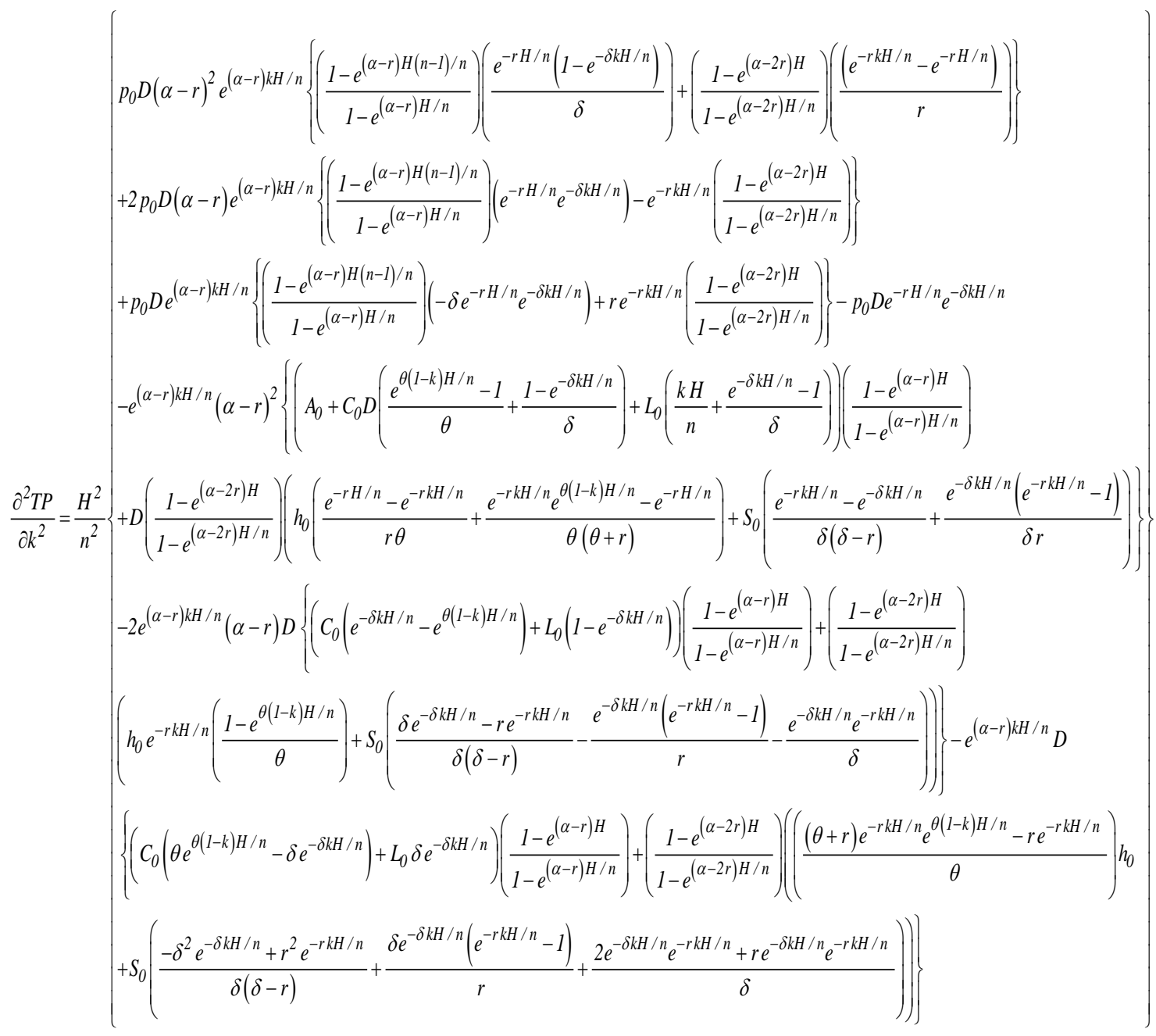


However the second derivative of the present worth of total profit $\operatorname{TP}(k, n)$ is a very complicated function, thus it is very difficult to prove concavity mathematically. Therefore, the concavity of the present worth of total profit has been established graphically (on several data sets) with the help of Maple (Fig. 2).

\section{Special Cases}

In this section, we will discuss some special cases that influence the total profit.

Case 1.In this case complete backlogging is considered i.e. $\delta=0$ then the total profit becomes

$$
\begin{aligned}
T P(k, n)= & p_{0} D e^{(\alpha-r) k H / n}\left(\frac{1-e^{(\alpha-2 r) H}}{1-e^{(\alpha-2 r) H / n}}\right)\left(\frac{e^{-r k H / n}-e^{-r H / n}}{r}\right)-e^{(\alpha-r) k H / n}\left\{A_{0}\left(\frac{1-e^{(\alpha-r) H}}{1-e^{(\alpha-r) H / n}}\right)+C_{0} D\left(\frac{1-e^{(\alpha-r) H}}{1-e^{(\alpha-r) H / n}}\right)\right. \\
& \left(\frac{e^{\theta(1-k) H / n}-1}{\theta}\right)+h_{0} D\left(\frac{1-e^{(\alpha-2 r) H}}{1-e^{(\alpha-2 r) H / n}}\right)\left(\frac{e^{-r H / n}-e^{-r k H / n}}{r \theta}+\frac{e^{-r k H / n} e^{\theta(1-k) H / n}-e^{-r H / n}}{\theta(\theta+r)}\right) \\
& \left.+S_{0} D\left(\frac{1-e^{(\alpha-2 r) H}}{1-e^{(\alpha-2 r) H / n}}\right)\left(\frac{1-e^{-r k H / n}}{r^{2}}-\frac{k H}{n} \frac{1}{r}\right)\right\}
\end{aligned}
$$

Case 2.If there is no deterioration i.e. $\theta=0$, then Eq. (16) reduces

$$
\begin{aligned}
T P(k, n)= & p_{0} D e^{(\alpha-r) k H / n}\left\{\left(\frac{1-e^{(\alpha-2 r) H}}{1-e^{(\alpha-2 r) H / n}}\right)\left(\frac{e^{-r k H / n}-e^{-r H / n}}{r}\right)+\left(\frac{1-e^{(\alpha-r) H(n-1) / n}}{1-e^{(\alpha-r) H / n}}\right)\left(\frac{\left.e^{-r H / n}\left(1-e^{-\delta k H / n}\right)\right)}{\delta}\right)\right\}+p_{0} D \\
& \left(\frac{e^{-r H / n}\left(1-e^{-\delta k H / n}\right)}{\delta}\right)-e^{(\alpha-r) k H / n}\left\{A_{0}\left(\frac{1-e^{(\alpha-r) H}}{1-e^{(\alpha-r) H / n}}\right)+C_{0} D\left(\frac{1-e^{(\alpha-r) H}}{1-e^{(\alpha-r) H / n}}\right)\left(\frac{(1-k) H}{n}+\frac{1-e^{-\delta k H / n}}{\delta}\right)\right. \\
& +h_{0} D\left(\frac{1-e^{(\alpha-2 r) H}}{1-e^{(\alpha-2 r) H / n}}\right)\left(\frac{(1-k) H}{n} \frac{e^{-r k H / n}}{r}+\frac{e^{-r H / n}-e^{-r k H / n}}{r^{2}}\right)+S_{0} D\left(\frac{1-e^{(\alpha-2 r) H}}{1-e^{(\alpha-2 r) H / n}}\right) \\
& \left.\left(\frac{e^{-r k H / n}-e^{-\delta k H / n}}{\delta(\delta-r)}+\frac{e^{-\delta k H / n}\left(e^{-r k H / n}-1\right)}{\delta r}\right)+L_{0} D\left(\frac{1-e^{(\alpha-r) H}}{1-e^{(\alpha-r) H / n}}\right)\left(\frac{k H}{n}+\frac{e^{-\delta k H / n}-1}{\delta}\right)\right\}
\end{aligned}
$$

Case 3.When there is no inflation and time value of money $(\alpha, r=0)$, then the total profit of the system is

$$
\begin{aligned}
T P(k, n)= & p_{0} D\left\{(1-k)\left(\frac{H}{n}\right)+\frac{\left(1-e^{-\delta k H / n}\right)}{\delta}\right\}-\left\{A_{0}+C_{0} D\left(\frac{e^{\theta(1-k) H / n}-1}{\theta}+\frac{1-e^{-\delta k H / n}}{\delta}\right)+h_{0} D\left(\frac{e^{\theta(1-k) H / n}-1}{\theta}-(1-k)\left(\frac{H}{n}\right)\right)\right. \\
& \left.+\frac{S_{0} D}{\delta}\left(\frac{\left(1-e^{-\delta k H / n}\right)}{\delta}-e^{-\delta k H / n} \frac{k H}{n}\right)+L_{0} D\left(\frac{k H}{n}+\frac{e^{-\delta k H / n}-1}{\delta}\right)\right\}
\end{aligned}
$$




\section{Solution Procedure}

In order to obtain the values of $k$ and $n$ which maximize the total profit $T P(k, n)$, the following procedure (Jaggi et al., 2006) is adopted.

Step 1: Solve Eq. (17) for $k$ by substituting $n=n_{p}$ and $n=n_{p}+1$, the corresponding values

of $k$ are $k_{n_{p}}$ and $k_{n_{p+1}}$, respectively, $\left(n_{p}=1,2, \ldots \ldots.\right)$.

Step 2: Compute $T P\left(k_{n_{p}}, n_{p}\right)$ and $T P\left(k_{n_{p}+1}, n_{p}+1\right)$.

Step 3: If $T P\left(k_{n_{p}}, n_{p}\right) \geq T P\left(k_{n_{p}+1}, n_{p}+1\right)$, then the optimal values of $k$ and $n$ are $k=k_{n_{p}}$ and $n=n_{p}$. The optimal value of $T$ can be obtained using the relation $T=H / n$ while the optimal value of $T P(k, n)$ can be obtained by substituting $k$ and $n$ in Eq. (16) and optimal lot size $\left(Q_{i}\right)$ for $i=1,2, \ldots, n$ can be obtained from Equation (7). Else, go to Step 4 .

Step 4: Replace $n_{p}$ by $n_{p}+1$ and go to Step 1 .

\section{Numerical Examples}

Let us consider an inventory system with following data:

Example: 1

Le $A_{0}=400, D_{0}=300, C_{0}=50, h_{0}=10, S_{0}=35, L_{0}=42, p_{0}=75, H=2, \theta=.08, \delta=.9, \alpha=.05, r=.12$ in appropriate units.

Solution: Using the solution procedure and with the help of software MS- Excel Solver and Maple-15, we get the results as shown in Table 1(a)

Table 1(a)

Optimal solution of Example 1

\begin{tabular}{ccccc}
\hline$i$ & $k_{i}$ & $T_{i}$ (Days) & $Q_{i}$ & $T P_{i}$ \\
\hline 1 & 0.16 & 730 & 622 & 2544.86 \\
2 & 0.17 & 365 & 304 & 5815.73 \\
3 & 0.20 & 243 & 201 & 6666.67 \\
4 & 0.24 & 182 & 150 & 6942.69 \\
5 & $\mathbf{0 . 2 8}$ & $\mathbf{1 4 6}$ & $\mathbf{1 1 9}$ & $\mathbf{6 9 9 4 . 8 6}$ \\
6 & 0.32 & 121 & 99 & 6936.97 \\
7 & 0.37 & 104 & 84 & 6816.91 \\
8 & 0.41 & 91 & 74 & 6658.32 \\
9 & 0.45 & 81 & 65 & 6474.19 \\
10 & 0.50 & 73 & 59 & 3272.31 \\
\hline
\end{tabular}

From this table, we observe that for number of replenishments $n=5$, the present worth of total profit is maximized. Hence the optimal solution is given as $n=5, k=.28, T=146, T P(n, k)=6994.86, Q=119$.Moreover the optimal replenishment schedule is given in Table 1(b). Further, the concavity of total profit function is shown in Fig. 2. 
Table 1(b)

The optimal replenishment schedule of Example 1

\begin{tabular}{ccccc}
\hline$i$ & $t_{i 1}$ & $t_{i}$ & $t_{i-1}$ & $Q_{i}$ \\
\hline 1 & 0.112 & 0.4 & 0 & 119 \\
2 & 0.512 & 0.8 & 0.4 & 119 \\
3 & 0.912 & 1.2 & 0.8 & 119 \\
4 & 1.312 & 1.6 & 1.2 & 119 \\
5 & 1.712 & 2.0 & 1.6 & 119 \\
\hline
\end{tabular}

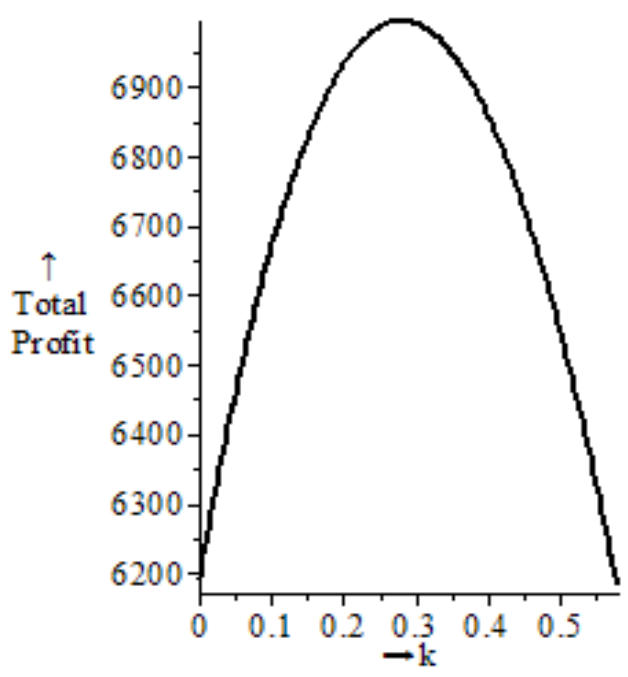

Fig. 2. Concavity of Present worth of total profit with respect to $k$

\section{Example: 2}

Let $A_{0}=400, D_{0}=300, C_{0}=50, h_{0}=10, S_{0}=35, L_{0}=42, p_{0}=75, H=2, \theta=.10, \delta=.9, \alpha=.05, r=.12$ in appropriate units.

Solution: The optimal solution in this case is as follows:

$n=6, k=.29, T=121, T P(n, k)=6948.95, Q=117$

Further, the concavity of total profit function is shown in Fig. 3.

\section{Example: 3}

Let $A_{0}=400, D_{0}=300, C_{0}=50, h_{0}=10, S_{0}=35, L_{0}=42, p_{0}=75, H=2, \theta=.20, \delta=.9, \alpha=.08, r=.12$ in appropriate units.

Solution: The optimal solution in this case is as follows:

$$
n=6, k=.36, T=121, T P(n, k)=6722.05, Q=104
$$

where $Q$ is the lot size in each replenishment cycle. Further, the concavity of total profit function is shown in Fig. 4.

\section{Example: 4}

Let $A_{0}=400, D_{0}=300, C_{0}=50, h_{0}=10, S_{0}=35, L_{0}=42, p_{0}=75, H=2, \theta=.30, \delta=.9, \alpha=.08, r=.12$ in appropriate units.

Solution: The optimal solution in this case is as follows: 
$n=7, k=.39, T=104, T P(n, k)=6524.87, Q=89$

Further, the concavity of total profit function is shown in Fig. 5.

\section{Example: 5}

Let $A_{0}=400, D_{0}=300, C_{0}=50, h_{0}=10, S_{0}=35, L_{0}=42, p_{0}=75, H=2, \theta=.08, \delta=.72, \alpha=.05, r=.12$ in appropriate units.

Solution: The optimal solution in this case is as follows:

$n=7, k=.32, T=104, T P(n, k)=7102.61, Q=120$

Further, the concavity of total profit function is shown in Fig. 6.

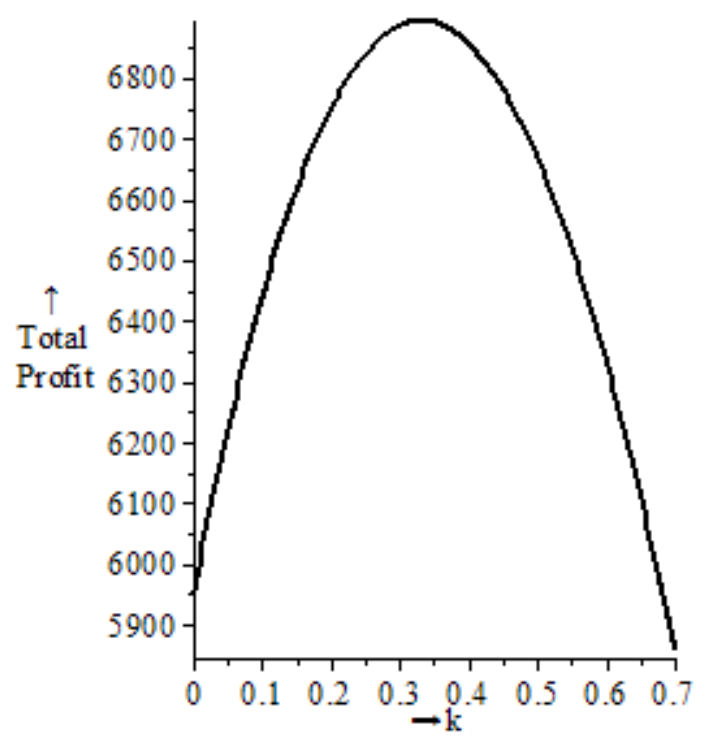

Fig. 3. When $\alpha=0.05$ and $\theta=0.10$

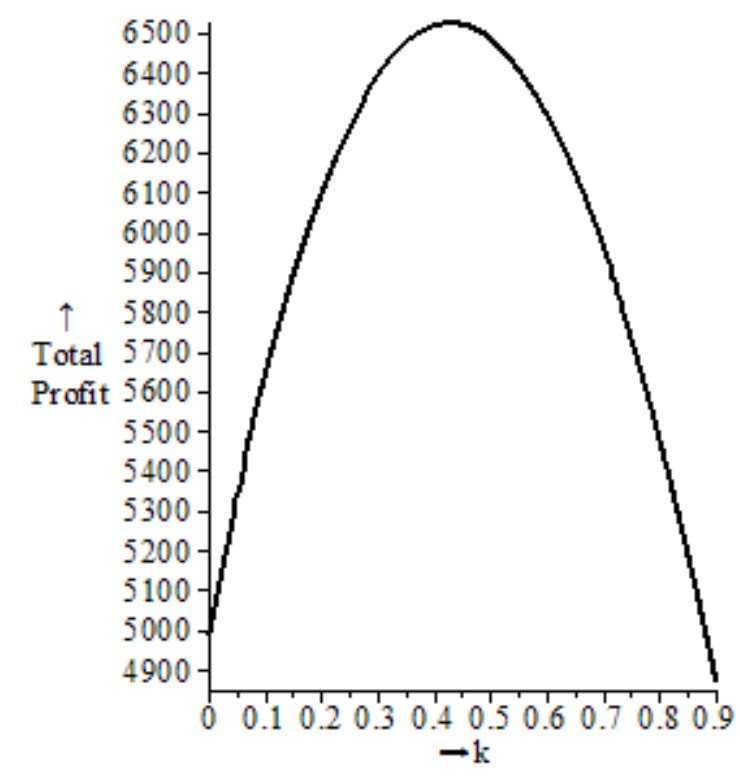

Fig. 5. When $\alpha=0.08$ and $\theta=0.30$

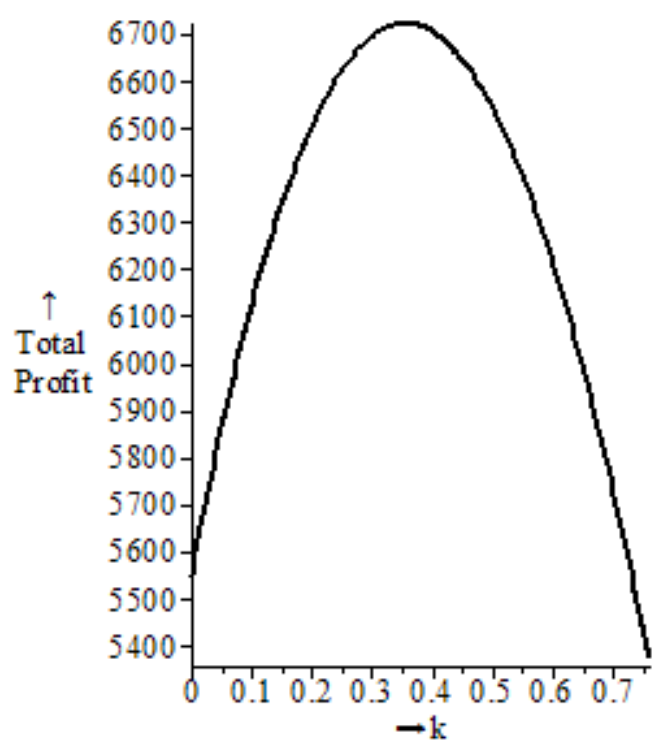

Fig. 4. When $\alpha=0.08$ and $\theta=0.20$

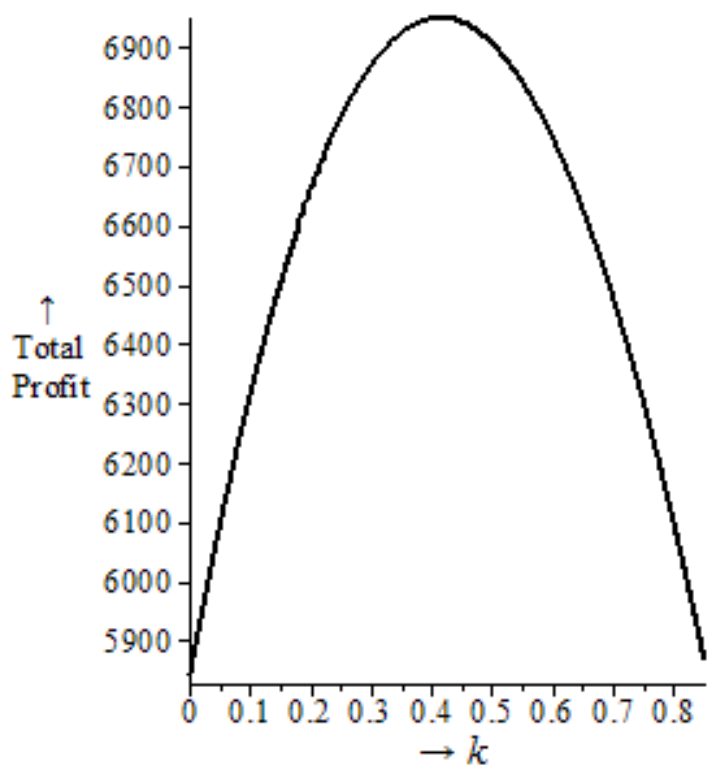

Fig. 6. When $\delta=0.72$ 


\section{Comparative analysis with special cases}

Table 2 represents a comparative study of the proposed model with different special cases. In case of complete backlogging the profit is lower as compared to the proposed model. Moreover, when there is no deterioration, then the profit for the retailer rises which is natural. Further in absence of inflation and time value of money the profit is little higher; since DCF approach helps in proper recognition of financial implication of opportunity cost in inventory analysis, so in absence of it the profit values may deviate.

Table 2

Optimal solution for different special cases.

\begin{tabular}{cccccc}
\hline Special Conditions & $n$ & $k$ & $T$ & $Q$ & $T P(n, k)$ \\
\hline Our Model & 5 & 0.28 & 146 & 119 & 6994.86 \\
$\delta=0$ & 2 & 0.35 & 365 & 200 & 4480.86 \\
$\theta=0$ & 4 & 0.12 & 183 & 150 & 7302.36 \\
$R=0$ & 1 & 0.16 & 730 & 622 & 7110.19 \\
\hline
\end{tabular}

\section{Sensitivity Analysis}

The change in the values of parameters may happen due to uncertainties in any decision-making situation. In order to examine the implications of these changes, the sensitivity analysis will be of great help in decision-making. Using the numerical example given in the preceding section, the sensitivity analysis of parameters $\alpha$ and $\theta$ has been done in Table 3 .

\section{Table 3}

Impact of $\alpha$ and $\theta$ on the optimal replenishment policy

\begin{tabular}{|c|c|c|c|c|}
\hline$\alpha \downarrow$ & $\theta \rightarrow$ & 0.10 & 0.20 & 0.30 \\
\hline \multirow{5}{*}{0.05} & $n$ & 6 & 7 & 8 \\
\hline & $k$ & 0.29 & 0.36 & 0.42 \\
\hline & $T$ (days) & 121.6 & 104.3 & 91.2 \\
\hline & $Q$ (units) & 117 & 103 & 93 \\
\hline & $T P(k, n)$ & 6948.95 & 6701.79 & 6520.18 \\
\hline \multirow{5}{*}{0.08} & $n$ & 5 & 6 & 7 \\
\hline & $k$ & 0.28 & 0.36 & 0.39 \\
\hline & $T$ (days) & 143.8 & 121.6 & 104.3 \\
\hline & $Q$ (units) & 119 & 104 & 89 \\
\hline & $T P(k, n)$ & 6976.33 & 6722.05 & 6524.87 \\
\hline \multirow{5}{*}{0.11} & $n$ & 4 & 5 & 6 \\
\hline & $k$ & 0.26 & 0.34 & 0.42 \\
\hline & $T$ (days) & 182.5 & 143.8 & 121.6 \\
\hline & $Q$ (units) & 120 & 106 & 86 \\
\hline & $T P(k, n)$ & 7021.01 & 6756.81 & 6552.96 \\
\hline
\end{tabular}

From Table 3, it is observed that:

When the rate of inflation $\alpha$ increases (with constant discount rate), then the present value of total profit $T P(k, n)$ and economic order quantity also increases significantly while optimal number 
of cycle's $n$ decreases (i.e. cycle length $T$ increases). The management repercussion of this result is quite apparent, since due to rising inflation the cost of goods increases, therefore it would be wise for the retailer to place a big order for a longer period of time in order to sustain his profits. Further, as the deterioration rate $\theta$ increases, then the present value of total profit $T P(k, n)$ and economic order quantity decreases noticeably whereas the optimal number of cycles $n$ increases (i.e. cycle length $T$ decreases). Since the worth of an item switches to zero because of deterioration, hence it would be economical for the retailer to order small lots for a shorter period of time so as to control the losses of deteriorating items.

Also, the effect of backlogging parameter $\delta$ on the optimal ordering policy has been shown in Table 4 .

\section{Table 4}

Impact of $\delta$ on the optimal replenishment policy

\begin{tabular}{cccccc}
\hline$\delta$ & $n$ & $k$ & $T$ (days) & $Q$ (units) & $T P(k, n)$ \\
\hline 0.72 & 7 & 0.32 & 104.3 & 120 & 7102.61 \\
0.81 & 6 & 0.30 & 125.4 & 119 & 7045.72 \\
0.99 & 5 & 0.26 & 143.8 & 117 & 6951.58 \\
1.08 & 4 & 0.24 & 182.5 & 116 & 6912.18 \\
\hline
\end{tabular}

Further, Table 4 implies that with an increase in backlogging parameter $\delta$, i.e., a decrease in backlogging rate, the present value of total profit and order quantity decreases substantially, whereas the cycle length increases (i.e. number of cycle's $n$ decreases). As a fraction of the order quantity is used to satisfy the backlogged demand, therefore a large value of backlogging rate, which means less of backlogged demand, decreases the order size. Eventually a smaller order lot results in stumpy profits.

\section{Conclusion}

In today's competitive market, uncertainty about future inflation may discourage investment and saving; and high inflation may lead to shortages of goods if consumers begin hoarding out of concern that prices will increase in future. Hence, ignoring the presence of inflation in inventory systems may yield deceptive results. In addition, stock out situations might turn out to be unfavorable for the organization if not handled vigilantly. Undeniably, the customer confronting a stock out situation should be the topmost priority for the retailer and must be given a satisfactory attention. Thus, accounting to such a scenario, these customers are being offered incentive i.e., by charging them the same price prevailing at the time of placing an order, instead of the inflated price of the next period. This aspect has not been addressed by the researchers yet in their modeling. Moreover, the different cost parameters including price are assumed to be varying from cycle to cycle, since this is basic repercussion of inflation. Therefore, a more pragmatic inventory model has been presented by incorporating some of the realistic phenomenon viz. deterioration, inflation and partially backlogged shortages over a fixed planning horizon, with time varying replenishment cycles, shortage intervals, and cost parameters; which is very closer to reality.

Findings have been validated with the help of a numerical example, and sensitivity analysis of the optimal solution with respect to various parameters has also been presented. It is observed that that inflation and deterioration, owing to their very nature, demonstrates a push and pull effect on the optimal order size. Moreover, it is perceived that with a reduction in the backlogged demand, the order quantity decreases, which eventually results in low profits. 
A further study would be to extend the proposed model with different types of variable demand such as price dependent demand, stock dependent demand etc. The model can also be developed under the condition of permissible delay in payments. Moreover the present investigation can be extended to include imprecise environments such as fuzzy, rough, bi-rough, random-rough, rough-random, etc.

\section{Acknowledgement}

The authors would like to thank the editor-in-chief and anonymous referees for their valuable comments which helped to improvise the present paper. The first two authors would like to acknowledge the support of the Research Grant No.: DRCH/R\&D/2014/6820, provided by the University of Delhi, Delhi, India for conducting this research.

\section{References}

Abad, P. L. (1996). Optimal pricing and lot sizing under conditions of perishability and partial backordering. Management Sciences, 42(8), 1093-1104.

Bakker, M., Riezebos, J., \& Teunter, R. H. (2012). Review of inventory systems with deterioration since 2001. European Journal of Operational Research, 221(2), 275-284.

Bansal, K. K. (2013). Inventory model for deteriorating items with the effect of inflation. International Journal of Application and Innovation in Engineering and Management, 2(5), 143-150.

Bhaula, B., \& Kumar, M. R. (2014). An economic order quantity model for weibull deteriorating items with stock dependent consumption rate and shortages under inflation. International Journal of Computing and Technology, 1(5), 196-204.

Bierman, H., \& Thomas, J. (1977). Inventory decisions under inflationary conditions. Decision Sciences, 8(1), 151-155.

Buzacott, J. A. (1975). Economic order quantities with inflation. Operational Research Quarterly, 26(3), 553-558.

Chang, H. J., \& Dye, C. Y. (1999). An EOQ model for deteriorating items with time varying demand and partial backlogging. Journal of Operational Research Society, 50(11), 1176-1182.

Chern, M. S., Yang, H. L., Teng, J. T., \& Papachristos, S. (2008). Partial backlogging inventory lot-size models for deteriorating items with fluctuating demand under inflation. European Journal of Operational Research, 191(1), 127-141.

Datta, T. K., \& Pal, A. K. (1991). Effects of inflation and time-value of money on an inventory model with linear time-dependent demand rate and shortages. European Journal of Operational Research, 52(2), 326-333.

Dye, C. Y., Ouyang, L. Y., \& Hsieh, T. P. (2007). Deterministic inventory model for deteriorating items with capacity constraint and time-proportional backlogging rate. European Journal of Operational Research, 178(3), 789-807.

Goyal S.K., Giri, B.C. (2001). Recent trends in modelling of deteriorating inventory. European Journal of Operational Research, 134(1), 1-16.

Jaggi, C. K., \& Goel, S. K. (2005). Economic ordering policies of deteriorating items under inflationary conditions. International Journal of Mathematical Sciences, 4(2), 287-298.

Jaggi, C. K., \& Khanna, A. (2008). Impact of inflation and credit policies on a production lot size model. Canadian Journal of Pure and Applied Sciences, 2(1), 243-249.

Jaggi, C. K., Aggarwal, K. K., \& Goel, S. K. (2006). Optimal order policy for deteriorating items with inflation induced demand. International Journal of Production Economics, 34(2), 151-155.

Misra, R. B. (1975). A study of inflationary effects on inventory systems. Logistic Spectrum, 9(3), 260268.

Misra, R. B. (1979). A note on optimal inventory management under inflation. Naval Research Logistics Quarterly, 26(1), 161-165.

Moon, I., Giri, B. C., \& Ko, B. (2005). Economic order quantity models for ameliorating/deteriorating items under inflation and time discounting. European Journal of Operational Research, 162(3), 773785. 
Raafat, F. (1991). Survey of literature on continuously deteriorating inventory model. Journal of Operational Research Society, 42(1), 27-37.

Shah, N. H., \& Shukla, K. T. (2009). Deteriorating inventory model for waiting time partial backlogging. Applied Mathematical Sciences, 3(9), 421-428.

Teng, J. T., \& Yang, H. L. (2004). Deterministic economic order quantity models with partial backlogging when demand and cost are fluctuating with time. Journal of Operational Research Society, 55(5), 495-503.

Teng, J. T., \& Yang, H. L. (2007). Deterministic inventory lot-size models with time-varying demand and cost under generalized holding costs. Information and Management Sciences, 18(2), 113-125.

Teng, J. T., Chang, H. J., Dye, C. Y. and Hung, C. H. (2002) 'An optimal replenishment policy for deteriorating items with time-varying demand and partial backlogging' Operations Research Letters, 30(6), 387-393.

Teng, J. T., Yang, H. L., \& Ouyang, L. Y. (2003). On an EOQ model for deteriorating items with timevarying demand and partial backlogging. Journal of Operational Research Society, 54(4), 432-436.

Thangam, A., \& Uthayakumar, R. (2010). An inventory model for deteriorating items with inflation induced demand and exponential partial backorders- a discounted cash flow approach. International Journal of Management Science and Engineering Management, 5(3), 170-174.

Wee, H. M., \& Law, S. T. (1999). Economic production lot size for deteriorating items taking account of time value of money. Computers and Operations Research, 26(6), 545-558.

Wee, H. M., \& Law, S. T. (2001). Replenishment and pricing policy for deteriorating items taking into account the time-value of money. International Journal of Production Economics, 71(1-3), 213-220.

Yang, H. L., Teng, J. T., \& Chern, M. S. (2001). Deterministic inventory lot-size models under inflation with shortages and deterioration for fluctuating demand. Naval Research Logistics, 48(2), 144-158.

Yang, H. L., Teng, J. T., \& Chern, M. S. (2010). An inventory model under inflation for deteriorating items with stock-dependent consumption rate and partial backlogging shortages. International Journal of Production Economics, 123, 8-19. 